\title{
Entrevista
}

\section{Entrevista con José Antonio Millán sobre el blog de EI futuro del libro}

Por Tomàs Baiget

Baiget, Tomàs. "Entrevista con José Antonio Millán sobre el blog de El futuro del libro”. En: El profesional de la información, 2007, marzo-abril, v. 16, n. 2, pp. 167-168.

DOI: 10.3145/epi.2007.mar.13

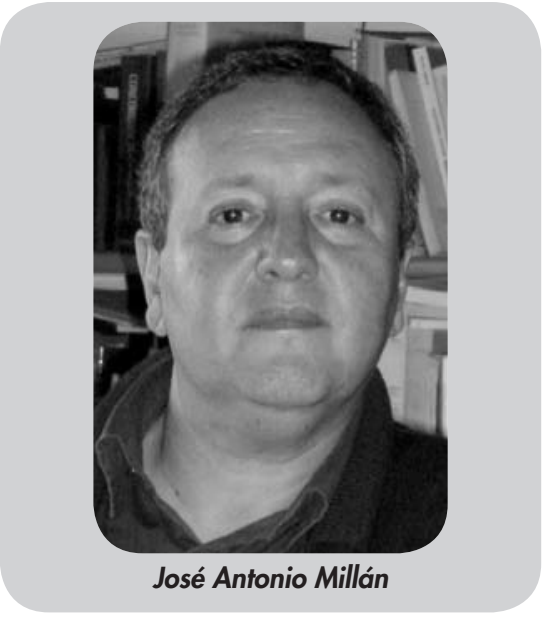

\section{¿Cuándo empezaste a escribir en blog?}

- En noviembre de 2001 inauguré en mi web una sección llamada sencillamente Blog (http://jamillan.com/blog.htm). Se trataba de una sucesión de notas, con la típica ordenación cronológica inversa. Era generalista: trataba tanto temas de edición digital como cualquier otro que me llamara la atención. Lo que me pareció interesante fue distinguir en una columna las fuentes digitales on line y en otra las de papel y otras off line (luego sustituí las columnas por el uso de Verdana y Times respectivamente).

A principios de 2003 independicé el blog sobre edición digital y lo llevé al apartado de la web "Libros y bitios" (http://jamillan.com/ lbblog.htm) y en junio dejé de hacer el blog generalista, porque me quitaba mucho tiempo, pero bien que lo siento: ¡con la de cosas interesantes que hay por ahí!...

\section{Luego lo pasaste a Blogger}

- No fue hasta junio del 2006. Me resistí mucho tiempo, aunque sabía que era absurdo seguir haciendo una especie de RSS a mano, y estar privado de comentarios, entre otras muchas cosas. Pero hay que pensar que el millar de páginas web de mi sitio están hechas artesanalmente, con el mismo programa que aprendí a usar en 1996, y el haberme plantado tecnológicamente es lo que me ha permitido dedicar esfuerzos a crear los contenidos, en vez de lidiar todo el rato con innovaciones. En el tránsito a Blogger me ayudó mucho Javier Candeira.

La verdad es que es un placer editar blogs como lo hago ahora, hasta tal extremo que me he enviciado y tengo tres. Los otros son El candidato melancólico, sobre lengua (http://jamillan.com/candidato/blog/) y El país que más..., sobre... este país (http://jamillan. com/estepa).

¿Cuándo empezaste el blog El futuro del libro? Y aquí resulta obligado preguntar por el mecenazgo de Google

- La verdad es que antes de conocer a nadie de Google había hecho algunos posicionamientos públicos sobre su proyecto de libros, que siempre me ha parecido muy valioso. Luego tuve distintos contactos con Marco Marinucci, de Google Libros, y un día del verano del 2006 me propusieron ser mecenas de mi blog, lo que básicamente implicaba por mi parte cambiarle el título, renovar su diseño gráfico y su usabilidad (en lo que me ha ayudado Eduardo Manchón), iy seguir haciendo lo que venía haciendo!, aunque con un apoyo externo, en vez de a pecho descubierto.

Claro, porque todo tu proyecto web lo has sostenido de forma independiente

- Sí, y ha empezado a resultar gravoso. Sin hablar de la dedicación personal: en los últimos doce meses mi sitio ha servido más de cuatro millones y medio de páginas, y a pesar de la ayuda de la publicidad que voy insertando, los costes del alojamiento son infames: ¿por qué en empresas de Estados Unidos cuesta la décima parte? A propósito (risas): acepto propuestas para cambiarme de hospedaje.

Pero a lo que iba: di el sí a Google, y el 27 de septiembre abrí el nuevo blog con una declaración pública en la que explicaba la nueva situación (http://jamillan. com/librosybitios/declara.htm). En general ha sido bien recibido; me hicieron comentarios muy bonitos, como el que decía "Esta es la era del nuevo poder de las inteligencias individuales, reconocidas social- 
mente sólo por el valor intrínseco de su producción intelectual". A lo que yo contestaría: “Ojalá!”.

¿Qué crees que significa ese movimiento, a nivel de la blogosfera?

- Bueno: para mí es sintomático que una empresa que está intentando cambiar un sector tradicional (el del libro) reconozca el valor de un blog independiente de discusión, ¡hasta el extremo de prohijarlo! Se han dado cuenta de la importancia que tiene el debate para clarificar una situación compleja.

Y la moraleja es clara: si una empresa nativa de la Red, con un conocimiento grandísimo de la acción dentro de ella, reconoce de ese modo el poder de un blog profesional, otras empresas con intereses diversos podrían aprender la lección...

Unapregunta obligada: ¿cuántos posts llevas escritos?, ¿y sobre qué temas?

- Unos setecientos, a lo largo de cinco años, pero con la mayor producción concentrada en los últimos dos.
La verdad es que ahora hay muchos blogs enfocados sobre algunos de los temas de los que yo escribo (bibliotecas virtuales, libros electrónicos, edición por línea, recuperación de información, impresión bajo pedido, tipografía, influencia de las nuevas tecnologías en el circuito editorial, en la escritura y la lectura...). Pero me gusta pensar que yo mantengo una mirada general sobre los cambios en una serie de terrenos independientes, pero que tienen mucho que ver entre sí. ¡Ah! y también tengo un ojo puesto en el pasado, porque la historia del libro y de la lectura está produciendo unos frutos excelentes en los últimos tiempos, y ayudan a comprender qué ocurre ahora, y qué puede ocurrir en el futuro.

Aunque sea una pregunta delicada: ¿para quién crees que son útiles los blogs?

- De entrada, para quien los hace (risas): educan en la disciplina y ayudan a objetivar ideas; yo recomiendo mucho su escritura. Pero luego ¡también pueden ser útiles para quien los lee!: los blogs temáticos o profesionales prestan un ser- vicio excelente a su comunidad, y no solamente de forma puntual. La verdad es que la tecnología actual permite combinar lo mejor de los dos mundos: por un lado tenemos el carácter atómico de los posts (con su inmediatez y su respuesta a estímulos próximos), y por otro su estructuración temática mediante etiquetas o, sencillamente, su acceso permanente a través de buscadores. Ahora están surgiendo agregadores de blogs temáticos (como LibWorm sobre blogs bibliotecarios, del que me enteré por DocuMenea), y en este terreno veremos muchas cosas que pondrán aún más en valor ese universo disperso de posts.

Los blogs son máquinas de pensar: en ellos cabe desde la nota de una línea (la simple pista de una publicación o un enlace), al pequeño ensayo, creado sin las imposiciones y condicionantes de escribir "todo un artículo". Si a esta libertad de planteamiento unimos los comentarios (a veces valiosísimos), tenemos un mecanismo de información e indagación excepcional.

\section{José Antonio Millán}

http://jamillan.com

\section{Te damos los ingredientes...}
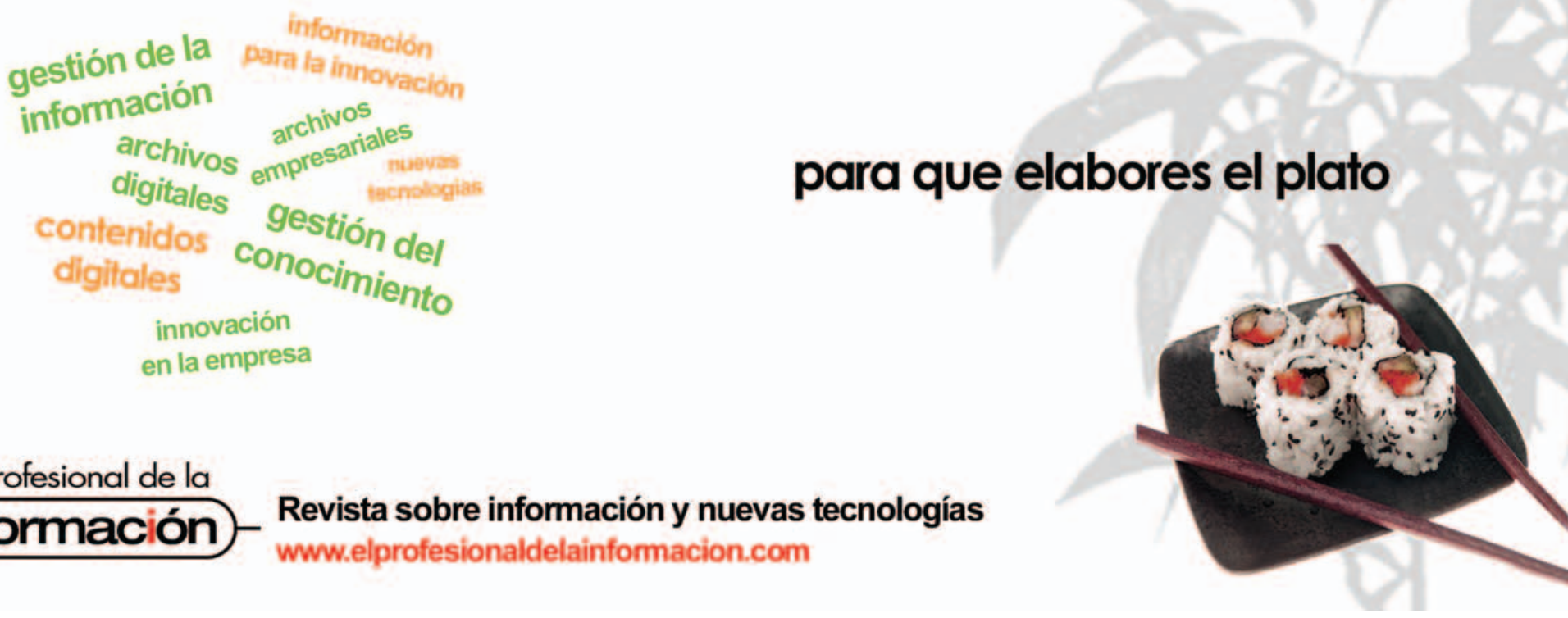